globulin therapy may also have played a protective role through its immunoregulatory effect. ${ }^{22}$

\section{Conclusion}

This case reaffirms that Mycoplasma pneumoniae should be considered in the differential diagnosis of an optic neuropathy preceded by a febrile illness. Moreover, it suggests that Mycoplasma may play a role in the induction of a white dot syndrome.

1 Murray HW, Masur H, Senterfit LB, Roberts RB. The protean manifestations of Mycoplasma pneumoniae infection in adults. Am f Med 1975; 58: 229-42.

2 Tuazon CU, Murray HW. Atypical pneumonias. In: Pennington JE, ed. Respiratory infections: diagnosis and mannington JE, ed. Respiratory infections: diagnosis and

3 Salzman MB, Sood SK, Slavin ML, Rubin LG. Ocular manifestations of Mycoplasma pneumoniae infection. Clin Infect Dis 1992; 14: 1137-9.

4 Pönkä A. Central nervous system manifestations associated with serologically verified Mycoplasma pneumoniae infection. Scand F Infect Dis 1980; 12: 175-84.

5 Clyde WA, Jr. Neurological syndromes and mycoplasmal infections. Arch Neurol 1980; 37: 65-6.

6 Clyde WA, Jr. Mycoplasmal diseases of the central nervous system. In: Scheld WM, Whitley RJ, Durack DT, eds. Infections of the central nervous system. New York: Raven Press, 1991: 283-93.

7 Anonymous. Mycoplasma pneumoniae. Lancet 1991; 337: $651-2$.

8 García CP, Petri EM, Iturralde RG, Bragado FG, Urech ET, Rivero Puente MI MA. Síndrome de Devic complicando una infección por Mycoplasma pneumoniae. Rev Clin Esp 1987; 181: $29-31$.
9 Novelli VM, Marshall WC. Optic disc swelling and Mycoplasma pneumoniae. Pediatr Infect Dis 1984; 3: 597.

10 Michel D, Laurent B, Granouillet R, Gaudin-Terrasse OD. Infections aiguees, récentes, et parfois persistantes à Mycoplasma pneumoniae, associées à des manifestations neurologiques. Rev Neurol (Paris) 1981; 137: 6-7.

11 Behan PO, Feldman RG, Segerra JM, Draper IT. Neurological aspects of mycoplasmal infection. Acta Neurol Scand 1986; 74: 314-22.

12 Yesnick L. Central nervous system complications of primary atypical pneumonia. Arch Intern Med 1956; 97: 93-8.

13 Verin Ph, Vildy A, Cales R, Bapt J-B. Une nouvelle étiologie de l'oedème des voies optiques prégéniculées: le Mycoplasma pneumoniae. Bull Soc Ophtalmol Fr 1980; 11: 1009-12.

14 Lerer RJ, Kalavsky SM. Central nervous system disease associated with Mycoplasma pneumoniae infection. Report of five cases and review of the literature. Pediatrics 1973; 52 : 658-68.

15 Yamamoto T, Inoue N, Yamashita Y, Shiraishi S, Murai Y. A case of bilateral optic neuritis and polyneuritis associated with Mycoplasma pneumoniae infection. Rinsho-Shinkeigaku 1983; 23: 404-9.

16 Baker AB, Noran HH. Changes in the central nervous system associated with encephalitis complicating pneumonia. Arch Intern Med 1945; 76: 146-53.

17 Robert H, Fischer C, Cloppet H, Trillet M, Schott B. Un cas d'atteinte neurologique (encéphalite et névrite optique) au cours di'une infection à Mycoplasma pneumoniae. Lyon Méd $1981 ; 2: 67-70$.

18 Rothstein EL, Kenny GE. Cranial neuropathy, myeloradiculopathy, and myositis complications of Mycoplasma pneumoniae infection. Arch Neurol 1979; 36: 476-7.

19 Fisher RS, Clark AW, Wolinksy IS, Parhad IM, Moses H, Mardiney MR. Postinfectious leukoencephalitis complicating Mycoplasma pneumoniae infection. Arch Neurol 1983. 40: 109-13.

20 Mandell GL, Douglas GR, Bennett JE. Principles and practice of infectious diseases. 3rd ed. Edinburgh: Churchill

21 Nussenblatt RB, Palestine AG. Uveitis. Fundamental and clinical practice. Chicago: Year Book 1989: 291-308.

22 Dwyer JM. Manipulating the immune system with immune globulin. N Englf Med 1992; 326: 107-16.

\title{
Orbital masquerade: hyperthyroidism and cavernous haemangioma of the orbit
}

Martin L Leib

Orbit and Plastics

Service, the Edward S

Harkness Eye Institute, Columbia-Presbyterian Medical Center and the College of Physicians and Surgeons, Columbia Surgeons, Columbia
University, New York Unive

M L Leib

Correspondence to:

Martin L Leib, MD

Mirector, Orbit and Plastics

Service, The Edward S

Harkness Eye Institute,

Columbia-Presbyterian

Medical Center, 635 West

Medical Center, 635 West
165 th Street, New York, New

165th Street, New York
York 10032, USA.

Accepted for publication

Accepted for pay 1993
Unilateral exophthalmos is a challenging clinical problem, and hyperthyroidism, statistically, is one of the most common causes in the adult population.

The possibility of other orbital inflammations or neoplasms coexisting with hyperthyroidism requires emphasis. In this report a case is presented where the patient had a history of chemical hyperthyroidism and cavernous haemangioma of the orbit previously unrecognised.

\section{Case report}

A 32-year-old woman presented on 15 September
1982 with a several week history of intermittent blurred vision in her right eye.

Her ocular history included variable exophthalmos in the right eye that was associated previously with documented hyperthyroidism of 3 years' duration. She had received a short course of propylthiouracil and propranolol, and is presently euthyroid.

On ophthalmic examination, her best corrected visual acuity was $20 / 20+2$ right eye and 20/15-1 left eye. The pupils were normal and the extraocular movements were full. She was orthophoric at distance and had 6 prism dioptres of exophoria at near. No diplopia could be elicited.

Orbital examination revealed mild resistance 
Figure 1 Illustration of axial proptosis with lateral displacement of the right eye.

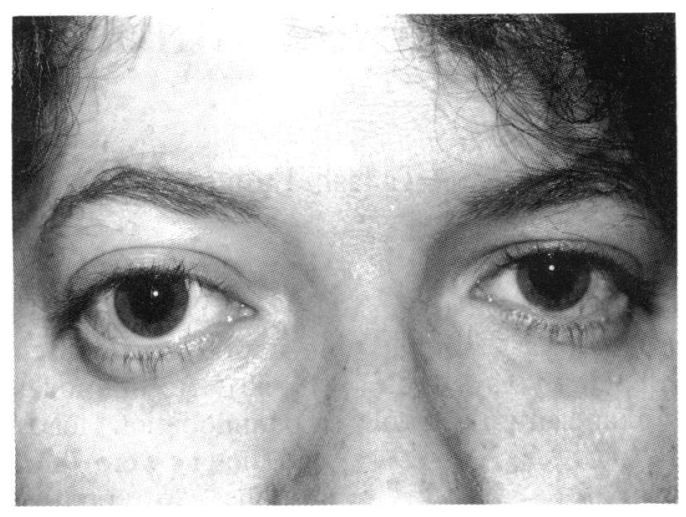

to retropulsion on the right with no lid lag or retraction. Exophthalmometry readings at a base of $106 \mathrm{~mm}$, measured $23 \mathrm{~mm}$ right eye and 18 $\mathrm{mm}$ left eye. (Fig 1). Colour vision testing was within normal limits in both eyes. However, the patient exhibited hesitation in her right eye while she easily identified the figures with her left. The intraocular pressure by applanation tonometry was normal in both eyes and rose insignificantly upon upgaze. The dilated fundus examination was within normal limits.

Because of unilateral proptosis, a paucity of clinical findings compatible with Graves' orbitopathy, and hesitation in the right eye on colour vision testing a high resolution orbital computed tomogram was ordered. The study demonstrated proptosis, normal muscle diameters, and a densely enhancing right intraconal tumour (Fig 2).

On 2 November 1982, a modified Kronlein orbitotomy was performed and a $23 \times 17 \times 14 \mathrm{~mm}$ purplish mass was removed without incident. The histopathological review was compatible with cavernous haemangioma.

Postoperatively, her best corrected visual acuity improved to $20 / 20+1$ right eye, and exophthalmometry readings returned to within $0.5 \mathrm{~mm}$ of each other. Colour vision testing was executed with equal facility in both eyes.

\section{Comment}

The differential diagnosis of unilateral exophthalmos is extensive, but certainly that associated with hyperthyroidism is high on the list in the general population. ${ }^{12}$ The diagnosis may, at times, be elusive in patients with euthyroid Graves' orbitopathy, a disease which has a variable and often asymmetric expression. Orbital computed tomography (CT) is superlative in identifying the typical myopathy and/or anterior migration of orbital fat, often in the contralateral, unsuspected eye as well.

Cavernous haemangioma of the orbit is probably a congenital vascular tumour, although some have proposed an acquired local haemodynamic disturbance. ${ }^{3}$ It usually presents in the

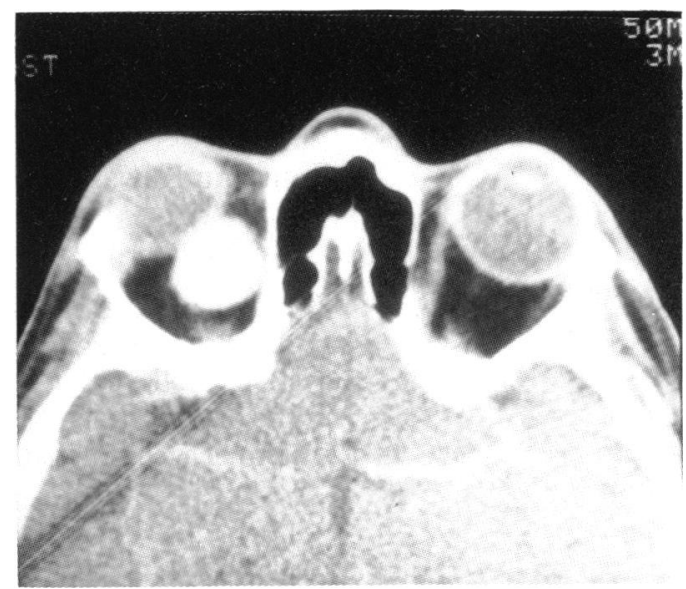

Figure 2 Computed tomogram in axial projection reveals proptosis, normal muscle diameters, and a wellcircumscribed, densely enhancing intraconal tumour.

second to fourth decade, and the symptoms characteristically develop over a number of years. ${ }^{45}$ Dynamic orbital CT (CT performed in multiple positions of gaze), highlights the cardinal radiographic features of cavernous haemangioma including absence of nerve or muscle attachments, contrast enhancement, secondary changes in the bony orbit, and usual location in the upper outer muscle cone sparing a small triangular space in the orbital apex..$^{6-8}$

The coexistence of these two diseases, namely hyperthyroidism and cavernous haemangioma of the orbit, remained unnoticed in this patient until her recent presentation. This report underscores the high level of suspicion one must evoke in the face of unilateral exophthalmos, even in the patient with known hyperthyroidism.

What is required is a meticulous scrutiny of the details in the clinical examination, so that an educated decision with strict criteria can be made when ordering orbital CT either to elucidate the mechanical forces at play in tailoring therapeutic goals, or to establish the coexistence of a suspected neoplasm when the clinical clues are apparent.

1 Moss HM. Diagnoses in 250 cases of orbital mass lesions including biopsy proved, clinical and $x$-ray diagnosis. Am f Ophthalmol 1962; 54: 761 .

2 Jones IS, Leib ML. Orbital disease. In: Collins JF, ed. Handbook of clinical ophthalmology. New York: Masson, 1982: 285

3 Harris GJ, Jakobiec FA. Cavernous hemangioma of the orbit. In: Jakobiec FA, ed. Ocular and adnexa tumors. Birmingham, In: Jakobiec FA, ed. Ocular and adnexa tumors. Birmingham, AL: Aesculapius, 1978: 741.

Hood C. Cavernous hemangioma of the orbit. Arch Ophthalmol 1970; 83: 49.

5 Kopelow SM, Foos RY, Straatsma BR, Hepler RS, Pearlman JT. Cavernous hemangioma of the orbit. Int Ophthalmol Clin 1971; 11: 113 .

6 Unsöld R, Hoyt WF, Newton TH. CT criteria of orbital hemangioma and their importance in the differential diagnosis of intraconal tumors. Klin Monatsbl Augenheilkd 1979; 175: 773 .

7 Leib ML, Trokel SL. Orbital computer-assisted tomography. In: Lessell S, Van Dalen JTW, eds. Neuro-ophthalmology II. Amsterdam: Excerpta Medica, 1982: 342 .

8 Leib ML, Trokel SL. Orbital computer-assisted tomography. In:-Lessell S, Van Dalen JTW, eds. Neuro-ophthalmology III. Amsterdam: Excerpta Medica, 1984. 